\title{
География населения как направление специализации кафедры экономической и социальной географии Московского педагогического государственного университета
}

\author{
С. А. Горохов ${ }^{1}$, Р. В. Дмитриев ${ }^{1,2}$, М. М. Агафошин ${ }^{3 凶}$ \\ ${ }^{1}$ Институт географии Российской академии наук, Российская Федераџия \\ (119017, г. Москва, Старомонетный пер., 29) \\ ${ }^{2}$ Институт Африки Российской академии наук, Российская Федераџия \\ (123001, г. Москва, ул. Спиридоновка, 30/1) \\ ${ }^{3}$ Московский педагогический государственный университет, Российская Федерация \\ (119991, г. Москва, ул. М. Пироговская, 1, стр. 1)
}

\begin{abstract}
Аннотация: Цель исследования - выявить особенности и установить тематическую последовательность экономико-географических исследований на кафедре экономической и социальной географии МПГУ. Основной метод исследования - исторический. Авторами собраны и проанализированы источники, содержащие сведения об основных направлениях научных исследований сотрудников и/ или выпускников кафедры. Обобщены аналитические и статистические материалы, позволяющее дополнить и расширить общую картину развития отечественной географии. Результаты исследования. В течение второй половины 1920-х и в 1930-е годы происходило зарождение географии населения в рамках районного направления отечественной экономической географии. В дальнейшем (1940-1960-е годы) кафедра стала ведущей в стране в области изучения географии населения СССР. Затем - в период с конца 1960-х годов и до начала XXI в. - основной акцент социогеографических исследований на кафедре постепенно переносился с СССР на зарубежные страны. В настоящее время кафедра - один из основных российский центров, ведущих исследовательскую деятельность в области этногеографии и географии религий. Выводы. Несмотря на тот факт, что за всю историю кафедры 1/3 защищенных ее аспирантами диссертаций приходится на географию населения, а $2 / 3$ - на географию хозяйства. Именно география населения в настоящее время представляет собой основное направление специализации - ее «лицо» в отечественной общественной географии.
\end{abstract}

Ключевые слова: экономико-географические исследования, географический факультет МПГУ, кафедра экономической и социальной географии, социальная география, география населения.

Источник финансирования: Статья подготовлена по материалам исследований по темам ГЗ Института географии РАН № 0148-2019-0008 и Института Африки РАН № 0192-2019-0021. Анализ публикаций (статьи в журналах и книги) выполнен в рамках темы ГЗ № 0148-2019-0008; анализ диссертационных работ выполнен в рамках темы ГЗ № 0192-2019-0021.

Для цитирования: Горохов С.А., Дмитриев Р. В., Агафошин М.М. География населения как направление специализации кафедры экономической и социальной географии Московского педагогического государственного университета // Вестник Воронежского государственного университета. Серия География. Геоэкология, 2020, № 4, c. 85-93. DOI: https://doi.org/10.17308/geo.2020.4/3069

(C) Горохов С.А., Дмитриев Р.В., Агафошин М.М., 2020

Агафошин Максим Михайлович, e-mail: agafoshinmm@gmail.com

cc) (i) Контент доступен под лицензией Creative Commons Attribution 4.0 License. 


\section{ВВЕДЕНИЕ}

Кафедра экономической географии была создана на географическом факультете Московского государственного педагогического института МГПИ (с 1990 г. - МПГУ) в 1934 году. Однако экономико-географические исследования начались предшественниками МГПИ значительно раньше - еще на Высших женских курсах (основаны в 1872 г., реорганизованы в 1918 г.) и во 2-м Московском государственном университете (19181930 гг.). Институциональную «привязку» они получили в 1925 году с созданием кафедры географии [2]. Ее сотрудниками во времена 2-го МГУ были С. В. Бернштейн-Коган, Н.Н. Баранский, Л. Д. Синицкий, В. А. Каменецкий, А. А. Рыбников, П. Н. Степанов, Н. П. Никитин. По существу кафедра была общегеографической и занималась вопросами и физической, и экономической географии. Первым заведующим кафедрой географии (19251930 гг.) был известный в ту пору экономико-географ, профессор С. В. Бернштейн-Коган - основоположник и один из создателей отечественной районной школы в экономической и социальной географии. Тем не менее, создание в 1934 году в МГПИ географического факультета и - в его составе - «новой» кафедры экономической географии (с 1997 г. - экономической и социальной географии), безусловно, привело к интенсификации научной деятельности на факультете. До и после Великой Отечественной войны кафедрой заведовали профессор Р. М. Кабо, член-корреспондент АН СССР Н.Н. Баранский, профессор Ю.Г. Саушкин, доцент М. Г. Соловьева. В разное время на кафедре работали профессора Н.И. Ляликов, В. В. Покшишевский, П. М. Алампиев, С. Н. Раковский, В. Я. Ром и другие. В 1968-2014 годах - более 45 лет, кафедру возглавлял академик РАО, доктор географических наук В.П. Максаковский, а с 2014 года и до настоящего времени кафедрой руководит доктор педагогических наук, профессор А. А. Лобжанидзе. 29 апреля 2016 года кафедре экономической и социальной географии географического факультета МПГУ присвоено имя академика РАО В. П. Максаковского.

\section{МАТЕРИАЛЫ ИССЛЕДОВАНИЯ}

Научно-теоретическую основу исследования составляют воспоминания и труды специалистов, учившихся в аспирантуре, работавших и работающих на кафедре экономической и социальной МПГУ [13]. Ценными источниками послужили работы по истории и теории науки, в которых ана- лизируется роль сотрудников кафедры в становлении и развитии отечественной социально-экономической географии $[8,22,23]$. Большое значение для исследования научной деятельности кафедры дал анализ защищенных аспирантами МГПИ-МПГУ диссертаций в различных диссертационных советах страны. Перечень советов и авторефераты были предоставлены ведущим инженером кафедры Л. Ю. Фроловой, а также организатором и директором музея истории географического факультета и мемориального кабинета академика РАО В.П. Максаковского Е. И. Федотовой.

\section{РЕЗУЛЬТАТЫ ИССЛЕДОВАНИЯ}

За время существования кафедры экономической и социальной географии МПГУ сложились три магистральных научных направления ее специализации - география населения, география хозяйства и методика преподавания географии в средней и высшей школе. В отдельные периоды на кафедре проводились исследования по исторической и политической географии, географии туризма и рекреационной географии, страноведению. Однако, на наш взгляд, именно вклад кафедры в зарождение и развитие отечественной география населения был особенно значимым.

Основы научной школы географии населения в МПГУ были заложены Леонтием Даниловичем Синицким, который, опираясь на антропогеографический подход [19], описал процесс и результат расселения человечества по Земле, а также охарактеризовал влияние окружающей среды на формирование расовых различий [20]. Первый заведующий кафедрой Сергей Владимирович Бернштейн-Коган в своих работах, в отличие от оппонентов-экономистов, отстаивал чисто географический подход в выборе направление развития экономической и социальной географии. Отечественная наука обязана С. В. Бернштейну-Когану появлением советской школы районной географии, которую он возглавлял на протяжении 1920-х годов. По мнению известного экономико-географа О. А. Константинова, «его учение сдвинуло экономическую географию с застывшей точки традиционной школы и указало нашей науке новую важную и с теоретической и с практической стороны область изучение районов и вообще всех вопросов экономического районирования» $[8$, с. 80$]$.

Однако расцвет географии населения как научного направления в стенах МГПИ и в стране в целом в советское время связан с деятельностью профессора Рафаила Михайловича Кабо, работав- 
шего на кафедре экономической географии МГПИ с 1934 по 1953 год в качестве профессора и в отдельные годы ее заведующего. Рафаила Михайловича по праву можно считать одним из основоположников отечественной географии населения и культурной географии [5; 6]. Этот период - золотой «век» экономической и социальной географии в МГПИ. Именно с него начинается история географии населения как важнейшего направления экономической и социальной географии в СССРРоссии. В 1941 году в журнале «География в школе» Р.М. Кабо выступил с программной статьей «Элементы географического изучения населения в СССР», в которой утверждал, что «ошибочно сводить географию людей к одной только географии их хозяйственной деятельности, как ни велико значение этой деятельности в жизни общества ... География человека должна охватить все стороны жизни человека, которые в той или иной степени связаны с освоением территории» [7, с. 52]. В этой статье автор предвосхитил появление многих современных направлений географии населения географии культуры и образа жизни, географии поселений, став одним из первых отечественных географов, обозначивших необходимость гуманитаризации географии. Как пишет А. А. Ткаченко, анализ работ Р. М. Кабо «создает впечатление, что Рафаил Михайлович считал более правильным и желательным название не «география населения», a «социально-культурная география», отводя в ней большое место взаимодействию человека с природой, культуре и образу жизни населения» [23, c. 171].

Другим сотрудником кафедры, чьи научные интересы лежали в области географии населения, был доцент, а затем профессор Николай Иванович Ляликов. Именно Н.И. Ляликов, проработав в МГПИ двадцать лет (1941-1961 гг.), стал автором первого в стране учебного пособия по географии населения [11], цикла статей по географии населения в журнале «География в школе» [12]. Именно Н. И. Ляликов ввел в науку широко используемое вплоть до настоящего времени понятие «главная (или основная) полоса расселения» [11].

Р. М. Кабо и Н. И. Ляликов разрабатывали принципиальные вопросы географии населения и создавали работы, определявшие пути ее дальнейшего развития на многие годы вперед [23]. Но список сотрудников МГПИ, внесших значительный вклад в развитие отечественной школы географии населения, не исчерпывается лишь этими именами. С 1937 по 1949 год на факультете работал и одно время был заведующим кафедрой Юлиан Глебович Саушкин, предложивший новую методику изучения сельского расселения [18].

Кроме того, в 1950-1960-е годы на кафедре экономической географии МГПИ работал профессор Вадим Вячеславович Покшишевский - ученик С. В. Бернштейн-Когана, один из крупнейших отечественных экономгеографов, основным направлением научных исследований которого была география населения и поселений. Вадим Вячеславович был одним из инициаторов проведения современных историко-демографических исследований $[14,15]$ и основоположником географического изучения миграций в СССР [2]. Исследования В. В. Покшишевского, посвященные историко-географическому изучению миграции населения, стали первыми значительными работами по географии миграций в отечественной географии.

Одним из главных показателей активности научной работы подразделения является количество защищенных в ней диссертаций - именно наличие учеников, получивших ученые степени, свидетельствует о формирование научной школы. Из научной школы географии населения МГПИ, безусловным лидером которой был Р.М. Кабо, вышла целая плеяда отечественных экономико-географов.

Под руководством Р. М. Кабо с 1939 по 1955 год в МГПИ было подготовлено и защищено 15 кандидатских диссертаций - в основном, по географии населения [7]. Среди его учеников наиболее известны С. И. Брук, С. А. Ковалев, Е. Л. Шувалов.

Сергей Александрович Ковалев, окончив МГПИ в 1946 году и поступив в аспирантуру, он по совету своего научного руководителя Р. М. Кабо начал заниматься изучением сельского расселения. В 1949 году С. А. Ковалев завершил здесь подготовку кандидатской диссертации на тему «География сельского расселения в пределах Черноземного центра» и представил ее к защите. Впоследствии С.А. Ковалев стал работать на географическом факультете МГУ, где защитил докторскую диссертацию и стал профессором. Своими статьями и книгами о сельском расселении он заложил основы крупной научной школы в области изучения сельского расселения и социальной географии.

Профессор, доктор географических наук Coломон Ильич Брук известен как специалист по этнодемографии и этногеографии, автор этнографических карт. Он считается родоначальником этнодемографии и этнической картографии в СССР. В 1950 году под руководством Р. М. Кабо на географическом факультете МГПИ С. И. Брук защиил 
кандидатскую диссертацию «Изменения в географии населения и хозяйства в связи с созданием Рыбинского водохранилища».

Профессор Ефим Лукич Шувалов - специалист в области географии населения и организатор науки, с 1967 по 1984 год - ректор Уральского государственного педагогического университета (Екатеринбург). В 1951 году им в МГПИ была защищена под руководством Р. М. Кабо кандидатская диссертация на тему «География сельского хозяйства северо-восточных районов Дагестанской АССР».

Под руководством Н.И. Ляликова с 1948 по 1961 год на географическом факультете МГПИ было защищено 7 кандидатских диссертаций, все они были по населенческой тематике. Среди его учеников - крупные географы, профессора и доктора наук Н.И. Блажко и В. Я. Любовный. Нина Ивановна Блажко организовала кафедру экономической географии в Казанском государственном университете со специализацией «экономгеографматематик», что положило начало новому научному направлению в экономической географии - математико-географическому моделированию социально-экономических территориальных систем [17]. Владимир Яковлевич Любовный - крупный специалист в области социально-экономических проблем развития городов и регионов, градостроительной и региональной политики, управления муниципальным и региональным развитием, академик Российской академии архитектуры и строительных наук. Им в 1962 году была защищена кандидатская диссертация, подготовленная за время обучения в аспирантуре на кафедре, на тему «Географические особенности формирования кадров промышленных предприятий городских поселений юго-востока Московской области».

В. В. Покшишевский с 1954 по 1972 год руководил 7 кандидатскими диссертациями, большинство из которых были выполнены в русле географии населения. Наибольшую известность среди его аспирантов получил Феликс Михайлович Листенгурт - доктор географических наук, специалист в области программно-целевого планирования систем населенных мест.

Таким образом, с 1941 до 1960-х годов, за очень короткий срок, на кафедре экономической географии МГПИ фактически были заложены основы отечественной школы географии населения - одного из главных направлений современной социально-экономической географии. Однако в дальнейшем география населения на кафедре начала постепенно терять свои лидирующие позиции, акцент исследований сместился на изучение географии хозяйства, что во многом было предопределено сферой научных интересов ее многолетнего заведующего В. П. Максаковского.

Важно отметить, что с начала 1960-х годов на кафедре экономической географии МГПИ основной исследовательский акцент в географии населения был перенесен с СССР на зарубежные страны. Эти изменения связаны прежде всего с деятельностью М. Г. Соловьевой и С. Н. Раковского.

Маргарита Григорьевна Соловьева - кандидат географических наук, доцент, заведующий кафедрой экономической географии географического факультета в 1950-1960 годах. Сфера ее научных интересов охватывала вопросы экономической и социальной географии США [21], географии населения стран Азии, в том числе, Афганистана [16] и Индии, географии религий. Под руководством М. Г. Соловьевой в 1953-1984 годах в МГПИ были защищены 8 кандидатских диссертаций, большинство из которых - по географии населения зарубежных стран.

Сергей Николаевич Раковский - доктор географических наук, профессор. Круг научных интересов С. Н. Раковского был очень широк. Он включал в первую очередь вопросы географии населения, политической географии и геополитики, экономической и социальной географии Германии и Китая. В 1991 году в Институте географии АН СССР им была защищена докторская диссертация «Миграции населения в зарубежных странах Восточной Европы». С 1970 по 2005 год под руководством С.Н. Раковского была защищена 21 кандидатская диссертация, более половины из них - по географии населения, в том числе стран Северной Европы и Магриба, а также Германии и Франции.

Продолжателем миграционной тематики научных исследований на кафедре стал ее выпускник Никита Владимирович Мкртчян, защитивший кандидатскую диссертацию в МПГУ в 1997 году на тему «Изменение межрайонных миграционных связей в современной России и ее регионах» (научный руководитель В. Я. Ром). Ныне Н. В. Мкртчян - ведущий научный сотрудник Центра демографических исследований Института демографии НИУ ВШЭ, один из крупнейших специалистов в области миграционных процессов в России.

Начиная со второй половины 2000-х годов, основными направлениями исследований в области географии населения на кафедре становятся этническая география (руководитель - А. А. Лобжанидзе) [10] и география религий (руководитель - 
География населения как направление специализащии кафедры экономической и социальной географии Московского педагогического государственного университета

С. А. Горохов) $[4,9]$. Они сохраняют этот статус и в настоящее время.

Александр Александрович Лобжанидзе - доктор педагогических наук, кандидат географических наук, профессор, президент Российской ассоциации учителей географии (РАУГ). В 2009 году А. А. Лобжанидзе защитил в МПГУ диссертацию на соискание доктора педагогических наук на тему «Этнокультурная парадигма школьного географического образования как средство реализации культурологического подхода». С 2014 года А. А. Лобжанидзе заведует кафедрой экономической и социальной географии МПГУ. Он первый заведующий из числа ее выпускников за всю 95-летнюю историю. Сфера научных интересов А. А. Лобжанидзе чрезвычайно обширна. Она включает вопросы методики преподавания географии в средней и высшей школе, этнологии и этногеографии, экономической географии России. Под его руководством в 2011-2012 гг. в МПГУ было защищено 3 диссертации на соискание степени кандидата географических наук. Среди его аспирантов-специалистов в области географии населения можно назвать Нури Валерьевича Багапша - выпускника МПГУ, а ныне - доцента кафедры географии Абхазского государственного университета, научного сотрудника отдела этнологии Абхазского института гуманитарных исследований имени Д. И. Гулиа Академии наук Абхазии.

Горохов Станислав Анатольевич - доктор географических наук, профессор, в прошлом - аспирант кафедры, защитивший в 1999 году в МПГУ кандидатскую диссертацию [3] под руководством академика РАО В. П. Максаковского. Это была первая диссертация в России по конфессиональной географии, подготовленная на зарубежном материале. В 2017 году в Институте географии РАН (научный консультант - В.Н. Стрелецкий) им была защищена первая в России докторская диссертация по географии религий. Работа посвящена выявлению особенностей прохождения циклов религиозной конкуренции разных видов в рамках уровней территориальной структуры конфессионального геопространства в долгосрочной исторической ретроспективе.

Среди учеников С. А. Горохова - выпускников МПГУ, специализирующихся в области географии населения, необходимо отметить преподавателя кафедры Максима Михайловича Агафошина, готовящего к защите диссертацию по географии миграций из арабских стран в Европу [1]. В своих исследованиях М.М. Агафошин впервые в отече- ственной географии анализирует миграционные процессы как один из определяющих факторов в изменении конфессиональной структуры населения в странах мира.

Еще два выпускника кафедры - ученики С. А. Горохова - ныне работают в Институте географии РАН и Институте Африки РАН. Это кандидаты географических наук - Руслан Васильевич Дмитриев и Иван Андреевич Захаров. Р. В. Дмитриев стал одним из последних аспирантов кафедры, защитившихся в МПГУ (2012 г.) до прекращения работы диссертационного совета на географическом факультете в 2013 году. Тема его работы: «Роль надагломерационных структур в формировании опорного каркаса расселения Индии». В настоящее время Р. В. Дмитриев в своих научных исследованиях основное внимание уделяет вопросам теоретической географии, в том числе теории центральных мест. И. А. Захаров защитил кандидатскую диссертацию в 2019 году в Институте географии РАН на тему «Трансформация конфессионального пространства Африки в XX - начале XXI веков». И. А. Захаровым на примере Африки впервые была разработана методика изучения процесса трансформации конфессионального геопространства, основанная на анализе динамики ключевых индикаторов состояния геопространств составляющих его религий.

\section{ЗАКЛЮЧЕНИЕ}

Таким образом, география населения и поселений как направление экономико-географических исследований на кафедре экономической и социальной географии МПГУ за почти столетний период своего развития прошла несколько этапов.

В течение второй половины 1920-х и в 1930-е годы происходило зарождение этого направления в рамках районного направления отечественной экономической географии. В дальнейшем (19401960-е годы), благодаря трудам Р.М. Кабо, Н.И. Ляликова, В.В. Покшишевского и других, кафедра стала ведущей в стране в области изучения географии населения СССР. В период с конца 1960-х годов и до начала XXI в. - основной акцент социогеографических исследований на кафедре постепенно переносился с СССР на зарубежные страны. В настоящее время кафедра экономической и социальной географии имени академика РАО В.П. Максаковского географического факультета МПГУ - один из основных российский центров, ведущих исследовательскую деятельность в области этногеографии и географии 
религий. Несмотря на тот факт, что за всю историю кафедры $1 / 3$ защищенных ее аспирантами диссертаций приходится на географию населения, a $2 / 3$ - на географию хозяйства ${ }^{1}$, именно география населения в настоящее время представляет собой основное направление специализации - eе «лицо» в отечественной общественной географии.

\section{СПИСОК ЛИТЕРАТУРЫ}

1. Агафошин М.М. Факторы миграции населения арабских стран Азии в ЕС // Известия выссших учебных заведений. Поволжский регион. Естественные науки, 2017, № 2 (18), с. 56-64. DOI: 10.21685/2307-9150-2017-2-7

2. Агирречу А. А. Становление и первые десятилетия развития кафедры экономической географии СССР (России) Московского университета: опыт историкогеографического исследования // Региональные исследования, 2014, № 4 (46), с. 145-158.

3. Горохов С. А., Лобжанидзе А. А., Дмитриев Р. В., Заяц Д. В., Агафошин М. М. География населения с основами демографии. Москва, ЮНИТИ-ДАНА, 2020. $83 \mathrm{c}$.

4. Горохов С.А., Христов Т.Т. Религии народов мира. Москва, Кнорус, 2013. 422 с.

5. Кабо Р. М. Города Западной Сибири: очерки историко-экономической географии (XVII - первая половина XIX вв.). Москва, Гос. изд-во географической лит., 1949. $217 \mathrm{c}$.

6. Кабо Р. М. Природа и человек в их взаимных отношениях как предмет социально-культурной географии // Вопросы географии. Сб. 5 (География населения). Москва, ОГИЗ, 1947, с. 67-126.

7. Кабо Р. М. Элементы географического изучения населения в СССР // География в школе, 1941, №3, c. $49-55$.

8. Константинов О.А. Предмет и метод экономической географии. М.-Л., Государственное издательство, 1926. $136 \mathrm{c}$.

9. Лобжанидзе А. А., Горохов С. А., Заяц Д. В. Эmногеография и география религий. Москва, Академия, 2005. $176 \mathrm{c}$.

10. Лобжанидзе А. А., Заяц Д. В. Этнокультурные регионы мира. Москва, Прометей, 2013. 240 с.
11. Ляликов Н.И. География населения СССР: Учебное пособие по курсу экономической географии СССР. Москва, тип. Госфиниздата, 1946. 24 с.

12. Ляликов Н.И. Очерки географии населения СССР. Очерк первый. Карта плотности населения СССР // География в школе, 1948, № 5, с. 15-23.

13. На географическом посту: сб. науч. статей, посвященных 80-летию В. П. Максаковского. Смоленск, Универсум, 2004. $484 \mathrm{c}$.

14. Покшишевский В.В. География населения зарубежных стран: Экономико-географические очерки. Москва, Просвещение, 1971. 176 с.

15. Покшишевский В.В. География населения СССР: Экономико-географические очерки. Москва, Просвещение, 1971. 176 с.

16. Рейсер М.Г. Афганистан: Экон.-геогр. характеристика. Москва, Гос. изд-во геогр. лит., 1946. 152 с.

17. Рубцов В. А., Трофимов А. М. Казанская экономико-географическая школа «Математико-географического моделирования пространственных систем» // Ученые записки Казанского государственного университета. Естественные науки, 2007, Т. 149, кн. 4, с. 204-214.

18. Саушкин Ю. Г. Географическое изучение сельских населенных пунктов Советского Союза // Bonpocbl географии. Сб. 5 (География населения). Москва, Географгиз, 1947, с. 53-66

19. Синицкий Л. Д. Очерки землеведения: (Антропогеография). Пг.; М., Книга, 1923. 281 с.

20. Синицкий Л.Д. Раса и среда. Москва, Тип. «И.Н. Кушнерев и К ${ }^{\circ} », 1907.48$ с.

21. Соловьева М.Г. Соединенные Штаты Америки. Москва, Мысль, 1974. 128 с.

22. Ткаченко А.А. Из истории географии населения: 75 лет со времени выхода программной статьи Р. М. Кабо// Региональные исследования, 2016, № 2 (52), c. $129-132$.

23. Ткаченко А. А. Кафедра экономической географии МГПИ и становление отечественной географии населения // Мат-ль Всеросс. науч. конф. с междунар. участием "Третьи Максаковские чтения» «Сочиально-экономическая география: теория, методология и практика преподавания». Москва, 2018, с. 169-174.

Конфликт интересов: Авторы декларируют отсутствие явных и потенциальных конфликтов интересов, связанных с публикацией настоящей статьи.

Поступила в редакиию 07.06.2020 Принята к публикащии 20.11.2020

\footnotetext{
1 Учитывались только диссертации, которые могут быть однозначно отнесены к тому или другому направлению.
} 


\title{
Population Geography as a Specialization Area of the Department of Economic and Social Geography of Moscow Pedagogical State University
}

\author{
S. A. Gorokhov ${ }^{1}$, R. V. Dmitriev ${ }^{1,2}$, M. M. Agafoshin ${ }^{3 凶}$ \\ ${ }^{l}$ Institute of Geography of the Russian Academy of Sciences, Russian Federation \\ (29, Staromonetny Per., Moscow, 119017) \\ ${ }^{2}$ Institute for African Studies of the Russian Academy of Sciences, Russian Federation \\ (30/1, Spiridonovka St., Moscow, 123001) \\ ${ }^{3}$ Moscow Pedagogical State University, Russian Federation \\ (1, M. Pirogovskaya St., Moscow, 119991)
}

\begin{abstract}
The authors have collected and analyzed sources of information containing details on the main area of scientific research of employees of the Department. A generalization of analytical and statistical materials allows to supplement and expand the aggregate picture of the development of national geography.

The purpose of the study is to identify features and establish a thematic sequence of economic and geographical research of the Department of Economic and Social Geography of the Moscow Pedagogical State University. The main research method is historical: the authors have collected and analyzed the sources containing information about the main areas of scientific research of the department. Analytical and statistical materials are summarized, they allow us to supplement and expand the overall picture of the development of the Russian geography. Results. During the second half of the 1920s and in the 1930s the population geography was arising within the framework of the regional direction of the Soviet economic geography. In the 1940s-1960s the department became the leading one in population geography in the USSR. At the end of the 1960s the population studies had been changing the direction "from" the USSR to foreign countries. At present, the department is one of the main Russian centers conducting research in the field of ethnogeography and geography of religions. Conclusion. Despite the fact that a third of all the department's $\mathrm{PhD}$ theses had been defended on the population geography, and two thirds - on the economic geography, the population geography was the main area of its specialization - its "face" in the Russian geography.
\end{abstract}

Key words: economic and geographical research, faculty of geography of the Moscow Pedagogical State University, department of economic and social geography, social geography, population geography.

Funding: The study was performed within state assignment of the Institute of Geography RAS No. 01482019-0008 and of the Institute for African Studies RAS No. 0192-2019-0021. The survey of publications (journal articles and books) was accomplished within State Assignment of the Institute of Geography RAS No. 0148-2019-0008; the survey of thesis papers was accomplished within State Assignment of the Institute for African Studies RAS No. 0192-2019-0021.

For citation: Gorokhov S. A., Dmitriev R. V., Agafoshin M. M. Memorial Population Geography as a Specialization Area of the Department of Economic and Social Geography of Moscow Pedagogical State University. Vestnik Voronezskogo gosudarstvennogo universiteta. Seria Geografia. Geoekologia, 2020, No. 4, pp. 85-93. (In Russ.) DOI: https://doi.org/10.17308/geo.2020.4/3069

(C) Gorokhov S.A., Dmitriev R.V., Agafoshin M.M., 2020

\aksim M. Agafoshin, e-mail: agafoshinmm@gmail.com

cc) (i) The content is available under Creative Commons Attribution 4.0 License. 


\section{REFERENCES}

1. Agafoshin M. M. Faktory migratsii naseleniya arabskikh stran Azii v ES [Factors of migration of population from Asian Arab countries into the EU]. University proceedings. Volga region. Natural sciences, 2017, no. 2 (18), pp. 56-64. (In Russ.). DOI: 10.21685/2307-9150-2017-2-7

2. Aguirrechu A. A. Stanovlenie i pervye desyatiletiya razvitiya kafedry ekonomicheskoy geografii SSSR (Rossii) Moskovskogo universiteta: opyt istoriko-geograficheskogo issledovaniya [Establishing and early decades of the department of economic geography of the USSR (Russia) at Moscow University: a historico-geographical study]. Regional research, 2014, no. 4 (46), pp. 145-158. (In Russ.)

3. Gorokhov S. A., Lobzhanidze A. A., Dmitriev R. V., Zayats D. V., Agafoshin M. M. Geografiya naseleniya s osnovami demografii [Geography of population with the basics of demography]. Moscow, UNITI-DANA, 2020. 83 p. (In Russ.)

4. Gorokhov S. A., Khristov T. T. Religii narodov mira [Religions of the world's nations]. M., Knorus, 2013.422 p. (In Russ.)

5. Kabo R. M. Goroda Zapadnoy Sibiri: ocherki istoriko-ekonomicheskoy geografii (XVII-pervaya polovi$n a X I X v v$.) [Cities of Western Siberia: essays on historical and economic geography (17th - first half of the 19th centuries)]. Moscow, Gos. izd-vo geograficheskoy lit., 1949. 217 p. (In Russ.)

6. Kabo R. M. [Nature and man in their mutual relations as a subject of socio-cultural geography]. In: Voprosy geografii. Sb. 5 (Geografiya naseleniya) [Problems of Geography. Vol. 135 (Geography of population)]. Moscow, OGIZ, 1947, pp. 67-126. (In Russ.)

7. Kabo R. M. Elementy geograficheskogo izucheniya naseleniya $\mathrm{v}$ SSSR [Elements of a geographical study of the population in the USSR]. Geografiya $v$ shkole, 1941, no. 3, pp. 49-55. (In Russ.)

8. Konstantinov O. A. Predmet i metod ekonomicheskoy geografii [The subject and method of economic geography]. M.-L., Gosudarstvennoe izdatel'stvo, 1926. 136 p. (In Russ.)

9. Lobzhanidze A. A., Gorokhov S. A., Zayats D. V. Etnogeografiya i geografiya religiy [Ethnogeography and geography of religions]. Moscow, Akademiya, 2005. 176 p. (In Russ.)

10. Lobzhanidze A. A., Zayats D. V. Etnokul'turnye regiony mira [Ethno-cultural regions of the world]. Moscow, Prometey, 2013. 240 p. (In Russ.)

11. Lyalikov N.I. Geografiya naseleniya SSSR: Uchebnoe posobie po kursu ekonomicheskoy geografii SSSR [Geography of population of the USSR: A manual on the course of economic geography of the USSR]. Moscow, Gosfinizdat, 1946. 24 p. (In Russ.)

12. Lyalikov N. I. Ocherki geografii naseleniya SSSR. Ocherk pervyy. Karta plotnosti naseleniya SSSR [Features on the geography of the population of the USSR. The first essay. Map of the population density of the USSR]. Geografiya $v$ shkole, 1948, no. 5, pp. 15-23. (In Russ.)
13. Na geograficheskom postu: sb. nauch. statey, posvyashchennykh 80-letiyu V.P. Maksakovskogo [At a geographical post: coll. scientific articles dedicated to the 80th anniversary of V.P. Maksakovskiy]. Smolensk, Universum, 2004. 484 p. (In Russ.)

14. Pokshishevskiy V. V. Geografiya naseleniya zarubezhnykh stran: Ekonomiko-geograficheskie ocherki [Geography of population of foreign countries: Economic and geographical features.]. Moscow, Prosveshchenie, 1971. 176 p. (In Russ.)

15. Pokshishevskiy V. V. Geografiya naseleniya SSSR: Ekonomiko-geograficheskie ocherki [Geography of population of the USSR: Economic and geographical essays]. Moscow, Prosveshchenie, 1971. 176 p. (In Russ.)

16. Reyser M. G. Afganistan: Ekon.-geogr. kharakteristika [Afghanistan: Economic-geography characteristic]. Moscow, Gos. izd-vo geogr. lit., 1946. 152 p. (In Russ.)

17. Rubtzov V.A., Trofimov A. M. Kazanskaya ekonomiko-geograficheskaya shkola "Matematiko-geograficheskogo modelirovaniya prostranstvennykh sistem" [Kazan economical-geographical school of matematicalgeographical modelling of spatial systems]. Uchenye Zapiski Kazanskogo Universiteta-Seriya Estestvennye Nauki, 2007, vol. 149, no. 4, pp. 204-214. (In Russ.)

18. Saushkin Yu. G. [Geographical study of rural settlements of the Soviet Union]. In: Voprosy geografii. Sb. 5 (Geografiya naseleniya) [Problems of Geography. Vol. 135 (Geography of population)]. M., OGIZ, 1947, pp. 53-66. (In Russ.)

19. Sinitskiy L.D. Ocherki zemlevedeniya: (Antropogeografiya) [Features on earth science: (Anthropogeography).]. Pg.; M., Kniga, 1923. 281 p. (In Russ.)

20. Sinitskiy L. D. Rasa i sreda [Race and environment]. Moscow, Publ. "I. N. Kushnerev i Ko", 1907. 48 p. (In Russ.)

21. Solov'eva M. G. Soedinennye Shtaty Ameriki [The United States of America]. Moscow, Mysl', 1974. 128 p. (In Russ.)

22. Tkachenko A. A. Iz istorii geografii naseleniya: 75 let so vremeni vykhoda programmnoy stat'i R. M. Kabo [From the history of population geography: 75 years since the publication of the basic article by R. M. Kabo]. Regional research, 2016, no. 2 (52), pp. 129-132. (In Russ.)

23. Tkachenko A.A. [The economic geography department in Moscow state pedagogical institute and a formation of Russian population geography]. In: Sotsial'no-ekonomicheskaya geografiya: teoriya, metodologiya i praktika prepodavaniya: mat-ly Vseross. nauch. konf. s mezhdunar. uchastiem "Tret'i Maksakovskie chteniya" [Socio-economic geography: theory, methodology and teaching practice: materials of the All-Russian scientific conf. "The 3rd Maksakovsky readings"]. Moscow, Publ. "Pero", 2018, pp. 169-174. (In Russ.)

Conflict of interest: The authors declare no information of obvious and potential conflicts of interest related to the publication of this article.

Received: 07.06.2020

Accepted: 20.11.2020 
Горохов Станислав Анатольевич

доктор географических наук, ведущий научный сотрудник Института географии РАН, г. Москва, Российская Федерация, ORCID: https://orcid.org/0000-0001-9984-6054, e-mail: stgorohov@yandex.ru

\section{Дмитриев Руслан Васильевич}

кандидат географических наук, старший научный сотрудник Института географии РАН, старший научный сотрудник Института Африки РАН, г. Москва, Российская Федерация, ORCID: https://orcid.org/0000-0003-4018-9832, e-mail: $\underline{\text { dmitrievrv@yandex.ru }}$

Агафошин Максим Михайлович

ассистент кафедры экономической и социальной географии имени академика РАО В.П. Максаковского МПГУ, г. Москва, Российская Федерация, ORCID: https://orcid.org/0000-0002-0245-0481, e-mail: agafoshinmm@gmail.com
Stanislav A. Gorokhov

Dr. Sci. (Geogr.), Leading Researcher, Institute of Geography of the Russian Academy of Sciences, Moscow, Russian Federation, ORCID: https://orcid.org/0000-0001-9984-6054, e-mail: stgorohov@yandex.ru

Ruslan V. Dmitriev

Cand. Sci. (Geogr.), Senior Researcher, Institute of Geography of the Russian Academy of Sciences, Institute for African Studies of the Russian Academy of Sciences, Moscow, Russian Federation, ORCID: https://orcid.org/0000-0003-4018-9832, e-mail: dmitrievrv@yandex.ru

Maksim M. Agafoshin

Assistant Lecturer, V.P. Maksakovskiy Department of Economic and Social Geography, Moscow Pedagogical State University, Moscow, Russian Federation, ORCID: https://orcid.org/0000-0002-0245-0481, e-mail: agafoshinmm@gmail.com 